

\title{
Diabetes-related cardiomyopathy: The sweet story of glucose overload from epidemiology to cellular pathways
}

\author{
M. Joubert, A. Manrique, B. Cariou, X. Prieur
}

\section{To cite this version:}

M. Joubert, A. Manrique, B. Cariou, X. Prieur. Diabetes-related cardiomyopathy: The sweet story of glucose overload from epidemiology to cellular pathways. Diabetes \& Metabolism, 2019, 45, pp.238 - 247. 10.1016/j.diabet.2018.07.003 . hal-03485033

\section{HAL Id: hal-03485033 https://hal.science/hal-03485033}

Submitted on 20 Dec 2021

HAL is a multi-disciplinary open access archive for the deposit and dissemination of scientific research documents, whether they are published or not. The documents may come from teaching and research institutions in France or abroad, or from public or private research centers.
L'archive ouverte pluridisciplinaire HAL, est destinée au dépôt et à la diffusion de documents scientifiques de niveau recherche, publiés ou non, émanant des établissements d'enseignement et de recherche français ou étrangers, des laboratoires publics ou privés.

\section{다)(1) $(5$}

Distributed under a Creative Commons Attribution - NonCommerciall 4.0 International 
Diabetes-related cardiomyopathy: the sweet story of glucose overload from epidemiology to cellular pathways

Michael JOUBERT $^{\mathrm{a}, \mathrm{b}}$, Alain MANRIQUE ${ }^{\mathrm{c}, \mathrm{b}}$, Bertrand CARIOU ${ }^{\mathrm{d}}$, Xavier PRIEUR ${ }^{\mathrm{e}}$

${ }^{a}$ Diabetes Care Unit; Caen University Hospital; 14033 Caen cedex; France

b EA4650; UNICAEN; 14000 Caen; France

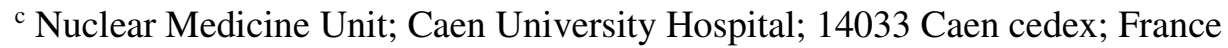

${ }^{\mathrm{d}}$ L'institut du thorax, INSERM, CNRS, UNIV Nantes, CHU Nantes, Nantes, F-44000, France

e L'institut du thorax, INSERM, CNRS, UNIV Nantes, Nantes, F-44000, France

\section{Corresponding author:}

Xavier Prieur

8 quai Moncousu, BP70721, 44007 Nantes cedex, France

Tel: +33228080166

Email: Xavier.prieur@univ-nantes.fr

Received: 2 May 2018

Accepted: 12 July 2018

\section{Declaration of interest}

M.J. has received honoraria and/or grants from Sanofi, Boehringer Ingelheim, Takeda, AstraZeneca, Novo Nordisk and Eli Lilly.

A.M. has no conflict of interest in the field of this manuscript.

B.C. is has taken part in advisory boards for AstraZeneca, Eli Lilly, Sanofi and Takeda.

X.P. received a grant from Boehringer Ingelheim.

\section{Funding}

This research is supported by the Fondation de France (FDF), Fondation pour la recherche médicale (FRM) and Société Francophone du diabète (SFD). 


\begin{abstract}
Type 2 diabetes (T2D) is a major risk factor for heart failure (HF). Although the number of cases of myocardial infarction in the T2D population has been reduced by $25 \%$ over the last 10 years, the incidence of HF is continuously increasing, making it the most worrying diabetes complication. This strongly reinforces the urgent need for innovative therapeutic interventions to prevent cardiac dysfunction in T2D patients. To this end, epidemiological, imaging and animal studies have aimed to highlight the mechanisms involved in the development of diabetic cardiomyopathy. Epidemiological observations clearly show that hyperglycaemia correlates with severity of cardiac dysfunction and mortality in T2D patients. Both animal and cellular studies have demonstrated that, in the context of diabetes, the heart loses its ability to utilize glucose, therefore leading to glucose overload in cardiomyocytes that, in turn, promotes oxidative stress, accumulation of advanced glycation endproducts (AGEs) and chronic activation of the hexosamine pathway. These have all been found to activate apoptosis and to alter heart contractility, calcium signalling and mitochondrial function. Although, in the past, tight glycaemic control has failed to improve cardiac function in T2D patients, recent clinical trials have reported cardiovascular benefit with hypoglycaemic antidiabetic drugs of the SGLT2-inhibitor family. This review, based on clinical evidence from mechanistic studies as well as several large clinical trials, covers 15 years of research, and strongly supports the idea that hyperglycaemia and glucose overload play a central role in the pathophysiology of diabetic cardiomyopathy.
\end{abstract}

Keywords: Diabetic cardiomyopathy; Glucotoxicity; Hexosamine pathway; Oral hypoglycaemic agents; SGLT2 inhibitors; Type 2 diabetes 


\section{Abbreviations}

AGEs: advanced glycation end-products

CAD: coronary artery disease

CMR: cardiac magnetic resonance

DMCMP: diabetes mellitus-related cardiomyopathy

DPP-4i: dipeptidyl peptidase-4 inhibitors

FAO: fatty acid oxidation

FDG: fluorodeoxyglucose

GLP-1RA: glucagon-like peptide-1 receptor agonist

HBP: hexosamine biosynthetic pathway

HF: heart failure

HFD: high-fat diet

HFpEF: heart failure with preserved left ventricular ejection fraction

HFrEF: heart failure with reduced left ventricular ejection fraction

LV: left ventricular

MACE: major adverse cardiovascular events

OGA: O-GlcNAcase

OGT: O-GlcNAc transferase

PET: positron emission tomography

PFK: phosphofructokinase

ROS: reactive oxygen species

SGLT2i: sodium-glucose cotransporter-2 inhibitor

T1D: type 1 diabetes

T2D: type 2 diabetes

ZDF: Zucker diabetic fatty 


\section{INTRODUCTION}

Type 2 diabetes (T2D) is an increasing worldwide epidemic with the fastest growth now observed in the developing countries. The estimated global prevalence of T2D reached 422 million people in 2014, with alarming predictions for the following decade [1]. Together with hypertension, hypercholesterolaemia and obesity, T2D is one of the four main cardiovascular risk factors, leading to more than one million cardiovascular (CV) deaths each year since 2010 [2]. In patients with T2D, two-thirds of deaths are related to CV disease that is partly driven by coronary artery disease (CAD) and hypertensive cardiomyopathy, given that hypertension is frequently associated to T2D [3,4]. Heart failure (HF) is also particularly frequent in patients with T2D, with a 2.5 -fold higher incidence than in patients without diabetes [5]. Although the number of myocardial infarction cases has been reduced by $25 \%$ in the T2D population over the past 10 years, the incidence of HF continues to increase, making it the most worrying of diabetes complications [6]. HF patient outcomes remain poor with a 5-year survival rate of about $50 \%$, leading to a poorer prognosis than with most cancers. In addition, HF patients are frequently hospitalized for episodes of acute decompensation, thereby representing a major human and economic burden with worrying prospects of worsening [7].

As mentioned above, ischaemic heart disease and hypertension are frequently associated with HF in $65 \%$ and $75 \%$ of T2D patients, respectively [8]. However, some patients with T2D display HF symptoms with no coronary, hypertensive, valvular, congenital, infiltrative, toxic or viral aetiologies, leading cardiologists to consider the concept of diabetes-mellitus-related cardiomyopathy (DMCMP). Nevertheless, the pathophysiology of DMCMP remains complex, as a number of factors may be implicated in this form of heart disease. Glucotoxicity, lipotoxicity, insulin resistance, hyperinsulinaemia, cardiac autonomic neuropathy and neurohormonal activation of the reninangiotensin-aldosterone system (RAAS) have all been found to contribute to the pathogenesis of such cardiomyopathy [9]. Thus, the present review presents the clinical and mechanistic data supporting the paramount involvement of glucose overload in the genesis and prognosis of DMCMP.

\section{CLINICAL ASSESSMENT AND CHARACTERIZATION}

\section{Historical descriptions of diabetic cardiomyopathy}

The first description of DMCMP was reported four decades ago, based on post-mortem analyses of patients with diabetes and HF symptoms. However, the absence of histopathological signs of the above-mentioned classic cardiac diseases led authors to conclude that these cardiac abnormalities were most likely directly related to diabetes [10]. The left ventricular (LV) hypertrophy and myocardial fibrosis observed in diabetes patients were also described in another study, along with increased myocardial lipid contents [11]. Since these initial reports were published, substantial information on DMCMP pathogenesis and clinical features has been accumulated. Increased myocardial deposition and cross-linking of collagen fibres are now recognized as histological/biochemical hallmarks of DMCMP [12,13]. In addition to such interstitial fibrosis, cardiomyocyte hypertrophy has also been 
described in some human and animal models, sometimes with coexistent atrophic cardiomyocytes and even apoptosis with a patchy distribution $[14,15]$.

\section{Diabetic cardiomyopathy: two distinct phenotypes}

The predominance of either cardiomyocyte hypertrophy or apoptosis identifies two distinct DMCMP phenotypes that can now be described thanks to recent advances in functional cardiac imaging [16], namely, heart failure with preserved LV ejection fraction (HFpEF), and heart failure with reduced LV ejection fraction (HFrEF). The most frequent echocardiography findings in patients with diabetes and HF combine a small LV cavity, thick LV walls, elevated LV filling pressures (reflecting diastolic dysfunction) and a large left atrium; as this restrictive cardiomyopathy is generally associated with a normal LV ejection fraction (LVEF), these patients are labelled HFpEF [17]. On the other hand, some patients with T2D present with echocardiography findings suggestive of the more classic dilated cardiomyopathy; this phenotype, which associates an enlarged LV cavity with a reduced LVEF, leads to HFrEF. Thus, HFpEF and HFrEF appear to be two distinct phenotypes rather than two successive stages with HFpEF eventually worsening to HFrEF.

The restrictive HFpEF phenotype represents the most frequent expression of DMCMP in T2D patients [16], and differentiating restrictive from dilated cardiomyopathy relies on echocardiography. However, cardiac magnetic resonance (CMR) imaging is increasingly being used for HF diagnosis and prognosis, as this tool can provide anatomical, structural and functional assessment of the heart, along with tissue characterization and vascular evaluation [18]. CMR is especially able to highlight LV stiffness, reflected early on by LV wall abnormalities and deformation, and diastolic dysfunction. In fact, one of the earliest findings of diabetic cardiomyopathy is abnormal rigidity of LV walls, revealed by CMR as reduced heart wall movements in various components of myocardial deformation (longitudinal, radial, circumferential strain). Such myocardial stiffness is mostly secondary to extracellular matrix and myocyte remodelling (detailed below). Decreased myocardial strain may also be observed in asymptomatic patients, where it can be considered a preclinical DMCMP marker in T2D patients with no signs of heart disease of some other aetiology. Impaired strain may even be detected by CMR in diabetes patients with no, or only slight, diastolic dysfunction as the earliest detectable myocardial abnormality of DMCMP. It is worth noting that, in asymptomatic T2D patients, altered myocardial strain is correlated with diabetes duration, suggesting that the myocardial stiffening process is an early finding with overall diabetes/hyperglycaemia exposure [19].

\section{Diabetes and heart failure: epidemiology}

Whatever the exact type of cardiomyopathy, it is clear that T2D is associated with HF. More than a decade ago, Nichols et al. [5] showed that, in a large retrospective database analysis, the incidence of HF was greater in patients with than in those without diabetes. This finding was particularly pronounced in patients aged $<65$ years, with a more than fourfold rate ratio of HF in T2D patients. 
Such an increased HF incidence in T2D was also found, albeit to a lesser extent, in older patients up to age 85 years. In this large cohort of $\sim 10,000$ patients, age was the strongest predictor for developing HF, with a $40 \%$ increased risk for every 5-year increment in age [5]. Similarly, another registry analysis found that the incidence of HF doubled in patients with diabetes for every decade over the age of 45 [8]. In one prospective study, Redfield et al. [20] evaluated both systolic and diastolic function, using a standardized echocardiography protocol, in $~ 2000$ randomly selected adults aged $>45$, and found that the prevalence of systolic and diastolic dysfunction was $157 \%$ and $78 \%$ higher, respectively, in patients with $v s$ without diabetes [20]. In addition, patients with HF often display insulin resistance, which can promote diabetes onset or worsen preexistent diabetes [21]. Indeed, several large cohort studies have reported that the incidence of diabetes is $30-50 \%$ in HF patients [22,23]. Taken together, these data strongly support the notion that T2D and HF are mutual promoters of each other.

Furthermore, this comorbid association leads to a deleterious situation with an increased incidence of HF worsening $(+37 \%)$ and death $(+28-30 \%)$ [22,24]. In elderly patients, the 5-year mortality was nearly doubled in patients presenting with both HF and diabetes compared with a $24 \%$ increase in HF in patients without diabetes [25]. In a post-hoc analysis of the Candesartan in Heart FailureAssessment of Reduction in Mortality and Morbidity (CHARM) study, the risk of HF death and hospitalization was assessed in patients with either HFrEF or HFpEF regardless of whether or not they had diabetes. In both cardiomyopathy phenotypes, diabetes proved to be an independent predictor of CV death or HF hospitalization with a hazard ratio (HR) of 1.60 for HFrEF and 2.0 for HFpEF patients [26]. Moreover, in patients with $\mathrm{HFpEF}$, it was demonstrated that all-cause mortality correlated with severity of diastolic dysfunction [20]. The presence of myocardial stiffness, the first event in the development of HFpEF, was also associated with increased mortality in asymptomatic patients with T2D, as recently described by Holland et al. [27] in a prospective cohort of 240 T2D patients followed for 10 years.

\section{Glycaemic control and prevalence of heart failure}

Beyond the clear association between HF and T2D described above, other data have shown that glycaemic control correlates with HF prevalence in patients with diabetes. In 2001, Iribarren et al. [28] demonstrated, in a large cohort study of nearly 50,000 patients, that HF hospitalizations and deaths were increased by $8 \%$ for every $1 \%$ increase in HbAlc levels. Moreover, multivariate analysis revealed that the increase in $\mathrm{HF}$ incidence related to $\mathrm{HbA} 1 \mathrm{c}$ was independent of other risk factors [28]. This was the first large-scale clinical study to demonstrate that the increased risk of HF was clearly related to glucose overload. Accordingly, a meta-analysis of 10 studies comprising 178,929 participants with diabetes confirmed that the overall adjusted risk ratio (RR) for HF was 1.15 [95\% confidence interval (CI): 1.10-1.21] for each 1\% increase in HbA1c [29]. In addition to HF incidence, hyperglycaemia was also associated with HF hospitalization and death. In a post-hoc analysis of the Prospective Comparison of ARNI with ACEI to Determine Impact on Global Mortality and Morbidity 
in Heart Failure (PARADIGM-HF) trial, the risk of HF hospitalization correlated (HR: 1.33-1.90) with increasing categories of HbA1c (from $<6 \%$ to $>7 \%$ ) [30].

This relationship between HbA1c and death or hospitalization due to HF was further confirmed by post-hoc analyses of the CHARM study [31]. In that study, diabetes was associated with a greater relative risk of HF hospitalization in patients with HFpEF (HR: 2.0, 95\% CI: 1.70-2.36) compared with HFrEF (HR: 1.60, 95\% CI: 1.44-1.77), bearing in mind that HFpEF is the more common DMCMP phenotype in T2D patients [26]. Several other studies have further confirmed that HF hospitalization is more frequent in patients with the highest HbA1c levels [32,33]. Considered altogether, this substantial body of observational clinical data supports the idea that hyperglycaemia is positively correlated with HF incidence and severity.

\section{Insights from type 1 diabetes}

In the setting of DMCMP, type 1 diabetes (T1D) presents with fewer pathophysiological confounding factors than in T2D. Indeed, T1D is characterized by autoimmune beta-cell destruction resulting in profound insulin deficiency, but with neither hyperinsulinaemia nor marked insulin resistance. In addition, lipid profile abnormalities are less frequent in T1D than in T2D patients, and mainly arise in cases of suboptimal glucose control (HbA1c > 7.5\%). In this latter context, total cholesterol is also higher, but high-density lipoprotein (HDL) cholesterol is lower and low-density lipoprotein (LDL) particle size is smaller compared with patients without diabetes, resulting in an atherogenic lipid profile [34]. In addition, triglyceride levels are not modified in T1D patients, not even in cases of above-target HbA1c, and hepatic steatosis is observed in < $10 \%$ of T1D patients, representing a sevenor eightfold lower prevalence than in patients with T2D [34,35]. In contrast to what is observed in T2D, the clinical data do not support cardiac lipid accumulation in patients with T1D [36]. Thus, these findings suggest that, in patients with T1D and HF, lipotoxicity is probably not as predominant as in T2D patients.

When the incidence of HF was assessed in T1D patients by a registry-based prospective case-control study, it showed a 3\% incidence of hospitalization for HF in 33,402 T1D patients compared with only $1 \%$ in the 166,228 matching control subjects, giving an HR of 4.69 (95\% CI: 3.64-6.04) after multiple adjustments for age, gender, diabetes duration and baseline comorbidities [37]. As reported in T2D, glycaemic control also appears to be a key parameter of DMCMP: HF incidence was demonstrated to increase along with $\mathrm{HbA1c}$, resulting in a nearly fourfold higher HF incidence in patients with $\mathrm{HbA1c}$ $>10.5 \%$ compared with $<6.5 \%$ [37].

Also, as observed in patients with T2D, the most frequent cardiac abnormality in T1D was diastolic rather than systolic dysfunction, with respective prevalences of $27 \%$ and $12 \%$ in a prospective echocardiography study of 157 asymptomatic T1D patients [38]. Similar findings were provided by a similar trial demonstrating that diastolic parameters were altered in T1D: in young patients aged 2032 years, their diastolic parameters corresponded to the normal values generally observed in healthy 
50-year-olds, thereby suggesting an accelerated stiffening process in patients with T1D [39]. An echocardiography strain trial of children with T1D has also reinforced this insight. In 100 young patients with T1D (mean age: $11.3 \pm 3.6$ years) with a duration of $5.1 \pm 3.1$ years, Labombarda et al. [40] found diastolic dysfunction and impaired longitudinal strain compared with 79 matching healthy children. Furthermore, longitudinal strain correlated with glycaemic control: the most altered myocardial deformation (decreased strain) was observed in patients with the highest HbA1c levels, suggesting yet again the strong association between glucose exposure and myocardial rigidity [40]. Moreover, it was previously reported that systolic and diastolic function were both improved in T1D patients after kidney-pancreas transplantation compared with patients with only kidney transplantation, in whom only systolic function was moderately improved, further highlighting the close relationship between blood glucose control and heart function [41].

\section{Contribution of imaging data}

Imaging features in patients with DMCMP are related to structural changes that lead to LV hypertrophy and cardiac remodelling together with further development of HF. In patients with diabetes, LV hypertrophy is a complex phenomenon, involving a mix of myocyte hypertrophy and increased extracellular volume related to fibrosis and collagen deposition [42]. CMR is widely used in both human [43] and preclinical models of CV disease [44] to obtain reproducible data on heart chamber size, myocardial mass, ventricular function and tissue characterization in vivo. In 50 asymptomatic patients with T2D, Cao et al. [45] demonstrated that myocardial extracellular volume (ECV) was significantly greater in diabetes patients than in controls $(27.4 \pm 2.5 \%$ vs $24.6 \pm 2.2 \%$; $P<$ 0.001), with no differences in myocardial mass. In addition, both T1 relaxation time and ECV were independently and positively associated with HbA1c levels, emphasizing the relationship between extracellular fibrosis and glycaemic control.

In early-stage disease, LV diastolic dysfunction is a common finding, present in 50-60\% of diabetes patients [46,47]. Using cluster analysis, Ernande et al. [48] recently highlighted the variety of cardiac profiles in T2D and the need to improve detection of subclinical LV dysfunction. In their study, the frequently observed diastolic abnormalities were worsened when T2D coexisted with hypertension and obesity [48]. In this context, abnormal global longitudinal strain is an early marker of the systolic dysfunction commonly seen in asymptomatic T2D patients despite normal diastolic function [49], thereby providing incremental prognostic information on top of diastolic dysfunction [50].

Data obtained in subjects with prediabetes, specifically identified by $\mathrm{HbA1c}$ levels between $5.7 \%$ and $6.4 \%$ with normal fasting glucose and normal glucose tolerance tests, have demonstrated an association between diastolic dysfunction and both $\mathrm{HbAlc}$ and advanced glycation end-products (AGEs) [51]. On the other hand, improvement of glycaemic control in patients with T2D can lead to improvement of global longitudinal strain and diastolic function [52]. 
Although imaging studies using positron emission tomography (PET) have widely investigated changes in cardiac metabolism, there is no clear evidence that excessive exposure of the heart to fatty acids and myocardial insulin resistance leads to subclinical myocardial dysfunction. Even in their highly detailed study, Rijzewijk et al. [53] failed to demonstrate any relationship between LV diastolic dysfunction and altered myocardial substrate metabolism.

\section{PRECLINICAL MODELS AND CELLULAR PATHWAYS}

\section{Changes in cardiac glucose metabolism in diabetic hearts}

The heart is a greedy organ that relies on a permanent energy supply. Carbohydrate is the unique energy substrate for fetal hearts, but this metabolic status changes with the introduction of milk and therefore fat in the diet. Mature hearts produce adenosine triphosphate (ATP) mainly through fatty acid oxidation (FAO), while carbohydrate represents only 10-20\% of their usual energy supply. However, energy metabolism in the normal heart is highly flexible and can use either one or the other, depending on plasma availability [54]. Insulin plays a key role in this metabolic flexibility and favours glucose uptake and utilization [55]. Mazumder et al. [56] showed that, in ob/ob T2D mouse model hearts, insulin failed to promote glucose uptake and utilization, whereas FAO was increased. This reflects a lack of metabolic flexibility in diabetic hearts, including greater reliance on fatty acids as fuel and a decreased ability to utilize glucose [57,58]. The same alterations in fuel utilization were reported in T1D rodent models $[59,60]$.

Regarding glucose uptake in T2D, the data are somewhat conflicting. While reduced glucose uptake under insulin stimulation in vitro is consistently observed in cardiomyocytes isolated from diabetic animals [56,61], data in vivo are more mixed. Fluorine-18 fluorodeoxyglucose $\left({ }^{18}\right.$ FDG $)-P E T$ is the imaging gold standard for assessment of glucose uptake in vivo. In 6-h fasted Zucker diabetic fatty (ZDF) rats, glucose uptake decreased in one study [62], but tended to be increased in another [63]. Also, ZDF rats under hyperinsulinaemic-euglycaemic clamps [64] and mice fed a high-fructose/highfat diet (HFD) [65] displayed reduced glucose uptakes compared with control animals, reflecting cardiac insulin resistance. In HFD-fed mice, FDG uptake in 4-h fasted animals was increased compared with standard-chow-fed animals [66]. Furthermore, in T2D lipodystrophic mice after 2-h fasting, an increase in glucose uptake was reported [67]. These discrepancies might be explained by differences in insulin levels achieved during PET imaging (physiologically by fasting conditions or through clamp techniques) and its ability to thwart (or not) cardiac insulin resistance. To date, several reports have demonstrated that insulin levels [68] and nutritional status [69] have major impacts on

${ }^{18}$ FDG-PET cardiac imaging. Nevertheless, to our knowledge, the nature of cardiac glucose uptake abnormalities in vivo remains uncertain in T2D.

On the other hand, the effect of diabetes on glucose utilization in the heart is well established (Fig. 1). In ZDF rats, glucose oxidation is strongly depressed due to a decrease in pyruvate dehydrogenase (PDH) activity even before the onset of cardiac dysfunction [70]. This decreased PDH activity is the 
result of acetyl coenzyme A (acetyl-CoA) accumulation due to the elevated rate of FAO in diabetic hearts [57]. PDH activation restores the glucose oxidation rate and normalizes diastolic function in diabetic rats, thereby supporting the central role of PDH inhibition in the development of diabetic cardiomyopathy [71]. In addition, increased FAO leads to citrate accumulation, which directly inhibits phosphofructokinase (PFK)-1 activity, the key enzyme catalyzing glucose oxidation in the heart [57]. Furthermore, insulin regulates cardiac PFK-2 activity, which synthesizes fructose 2,6-bisphosphate, an activator of PFK-1, the main glycolytic enzyme [55]. This is consistent with an increase in defective heart glucose oxidation of insulin-resistant mouse models with insulin treatment [56].

\section{Evidence for a central role of glucose overload in diabetic cardiac dysfunction}

In general, changes in diabetic heart glucose metabolism undoubtedly result in glucose overload [72]. As T2D is characterized by reciprocal alterations in both lipid and glucose utilization, it is difficult to precisely identify the contribution of each on its own to cardiomyopathy development. Similarly, it is always a challenge to differentiate insulin resistance per se from glucose overload. However, Montaigne et al. [73] elegantly demonstrated, in human cardiac biopsies, that mechanical dysfunction of cardiomyocytes correlated with mitochondrial dysfunction in patients with T2D, but not in obese insulin-sensitive patients. In addition, mitochondrial dysfunction correlated with $\mathrm{HbAlc}$, but not with homoeostasis model assessment for insulin resistance (HOMA-IR), thereby suggesting that hyperglycaemia, not insulin resistance, is the key component of cardiac dysfunction associated with T2D. Recently, diastolic dysfunction associated with glucose was reported in diabetic lipodystrophic mice in the absence of lipotoxic hallmarks [74]. In fact, treatment with sodium-glucose cotransporter2 inhibitors (SGLT2is) - a class of antidiabetic drugs that reduces glucotoxicity by promoting glycosuria-in several T2D rodent models improved cardiac function, thereby supporting the central role of chronic hyperglycaemia in cardiomyopathy development [74,75]. Mechanistic and cellular studies have also shown that glucose on its own can alter cardiomyocyte and heart properties, and that high-glucose exposure induces cardiomyocyte apoptosis [76] and endoplasmic reticulum (ER) stress through mammalian (or mechanistic) target of rapamycin (mTOR) signalling [77]. Moreover, glucose overload alters cardiomyocyte contact and contractile properties [78]. Thus, it seems clear that glucose overload is a key trigger in diabetes-associated cardiac dysfunction. What follows are some of the key pathways of heart glucotoxicity.

\section{High glucose increases ROS production via NADPH oxidase activation}

It has long been known that oxidative stress is involved in the pathophysiology of diabetic cardiomyopathy and HF in general [79]. Also, antioxidant N-acetylcysteine (NAC) prevents highglucose-induced apoptosis in isolated cardiomyocytes [80], which supports the idea that reactive oxygen species (ROS) production could be an important pharmacological target for preventing hyperglycaemia-induced cardiac dysfunction. 
Excess glucose can feed the pentose phosphate pathway, which produces nicotinamide adenine dinucleotide phosphate hydrogen (NADPH) starting from glucose-6-phosphate (G6P). NADPH is the substrate of cytosolic NADPH oxidase, an enzymatic complex that generates ROS. Therefore, glucose excess contributes to ROS production and, eventually, oxidative stress that can affect cardiac function (Fig. 1). In rodent models of HF, overexpression of NADPH oxidase subunits leads to oxidative stress [81,82], and similar findings have been described in humans, reinforcing the importance of NADPH oxidase as a source of ROS in heart disease [83]. In classic terms, it is acknowledged that glucose feeds ROS production through NADPH oxidase activity: G6P is metabolized by G6P dehydrogenase, which generates NADPH that, in turn, ultimately leads to ROS production by NADPH oxidase [84]. In isolated cardiomyocytes from $o b / o b$ mice [85] and in ZDF rat hearts [86], increased NADPH oxidase activity is associated with impaired calcium signalling and contractile properties, and is also involved in hyperglycaemia-induced cardiomyocyte apoptosis [87]. Interestingly, it has been suggested that induction of ROS production by exposure to high glucose levels in cardiomyocytes might be independent of glucose transporter type 4 (GLUT4) and that glucose transport might be mediated through SGLT1 [88] or sodium-myoinositol transporter 1 (SMIT1) [89] in an insulinindependent manner.

\section{Advanced glycation end-products in the heart}

In the context of defective glucose oxidation, increased glucose concentrations in cardiomyocytes together with oxidative status can promote AGEs as a result of non-enzymatic glucose reactions with proteins (glycation) [79]. AGEs provoke damage through three major mechanisms: (i) altered function of glycated proteins; (ii) modification of extracellular matrix properties; and (iii) activation of AGE receptors (RAGEs), which induce ROS production and contribute to oxidative stress [90]. AGEs are mostly involved in vascular complications associated with diabetes, although Ma et al. [91] have highlighted the role of AGEs in diabetic cardiomyopathy. Levels of AGEs such as methylglyoxal are elevated in the hearts of streptozotocin (STZ)-treated mice, a model of insulinopenic diabetes, and pharmacological inhibition of AGE production as well as RAGE knockdown improves cardiomyocyte mechanical properties [91]. Indeed, it has been shown that enrichment of reactive carbonyls such as methylglyoxal on ryanodine receptors alters ligand/receptor interactions and affects calcium signalling [92]. Similarly, glycation of the calcium pump sarcoplasmic/ER $\mathrm{Ca}^{2+}$-ATPase (SERCA2) alters its activity and compromises its relaxation properties in diabetic rat cardiomyocytes [93]. As observed in $d b / d b$ mice, a mouse model of T2D, the SGLT2i empagliflozin improved cardiac function, yet failed to normalize AGE levels in the heart [75]. These data show that normalizing glucose levels is not enough to reduce AGE levels and, instead, suggest that AGE normalization does not contribute to the beneficial effects of SGLT2is on the heart.

\section{Chronic activation of the hexosamine biosynthetic pathway (HBP)}


The HBP supplies the $\beta$-N-acetylglucosamine moiety (O-GlcNAc), which is O-linked by O-GlcNAc transferase (OGT) to numerous proteins on serine and threonine residues. This process of $\mathrm{O}-$ GlcNAcylation is a cellular signalling mechanism able to modulate the activity of several proteins; indeed, despite being a physiological mechanism, it has also been shown in vitro that chronic high glucose stimulates the HBP in cardiomyocytes and alters calcium cycling [94]. In STZ-induced diabetes, O-GlcNAc protein levels are increased, and overexpression of O-GlcNAcase (OGA), the enzyme that reverses OGT action, normalizes heart calcium signalling and contractile properties [95,96]. Regarding calcium signalling, O-GlcNAcylation levels of phospholamban, the calcium pump SERCA2 regulator, are increased in diabetic hearts and associated with transient ion calcium alterations and delays in calcium peaks in isolated cardiomyocytes [96,97]. Furthermore, Erickson et al. [98] demonstrated that acute hyperglycaemia induces O-GlcNAcylation of calmodulin-dependent protein kinase II (CaMKII), which regulates calcium export from ER to cytosol. Chronic OGlcNAcylation of CaMKII induces its autonomous activation, promoting spontaneous ER calcium release, arrhythmias and mechanical cardiac dysfunction. More important, elevated O-GlcNAcylated levels of CaMKII were found in the hearts of diabetes patients. Taken altogether, these elements directly link glucose overload and diastolic dysfunction in DMCMP through alteration of cardiomyocyte calcium homoeostasis by chronic O-GlcNAcylation of several key calcium signalling regulators.

Diastolic function also relies on cardiac contractile properties, while it has recently been shown that removing O-GlcNAc residues from myofilament proteins restores the calcium responses and contractile properties of muscle fibres isolated from diabetic hearts [99].

O-GlcNAcylation has also been involved in the regulation of another important contributor to diabetic cardiomyopathy: mitochondrial dysfunction. It was first revealed in cardiomyocytes that chronic glucose treatment promotes O-GlcNAcylation of several mitochondrial proteins, including complex I, III and IV subunits, while altering the activity of these complexes [100]. More important, OGA overexpression restores normal mitochondrial activity. Furthermore, it has been demonstrated that the O-GlcNAc dynamic (involving OGT and OGA) is required for normal mitochondrial function in cardiomyocytes, but is altered in diabetic hearts [101].

Finally, O-GlcNAcylation increases the activity of nuclear factor of activated T cells (NFAT), the transcription factor that regulates expression of hypertrophic genes (ANP, BNP...) [102,103]. HBP activation has therefore been implicated in most of the features of diabetic cardiomyopathy, including perturbed calcium handling, altered contractile properties, mitochondrial dysfunction and hypertrophy.

\section{THERAPEUTIC EFFECTS OF GLUCOSE-LOWERING ON HF MANAGEMENT IN T2D}

As discussed above, glucose overload appears to be central to the development of diabetic cardiomyopathy in observational reports. However, the effect of lowering glucose on the course of HF 
remains controversial. Thus, regarding glucose control and HF, the older therapeutic antidiabetic drug classes are discussed first.

The effects of metformin on HF have been a subject of debate: although initially contraindicated for patients with HF [104], a systematic review pointed out that, compared with other glucose-lowering drugs, metformin reduced mortality and had no adverse effects on HF [105]. However, to date, there has been no dedicated study to specifically address the effects of metformin on HF. Given that metformin is the first-line antidiabetic drug prescribed, such data would be of major public-health interest.

Thiazolidinediones (TZDs), such as pioglitazone and rosiglitazone, have been known to induce fluid retention ever since their approval, and were contraindicated from the outset in patients with New York Heart Association (NYHA) class III/IV HF [106]. Although used only for patients with NYHA class I/II with or without HF, the relative risk of HF hospitalization in prospective studies with these drugs ranges from 1.5- to 7-fold higher than other diabetes treatments [107]. TZD-related HF can mostly be explained by fluid retention through peroxisome proliferator-activated receptor (PPAR)- $\gamma$ mediated activation of collecting duct epithelial sodium channels (ENaCs) and sodium transporters in proximal tubules, although direct TZD effects on myocardial function have never been definitively ruled out [108]. Nevertheless, a recent study of patients with insulin resistance, but no diabetes, showed that the use of pioglitazone after a cerebrovascular event did not increase HF risk but, in fact, reduced the composite outcome of stroke, myocardial infarction and HF hospitalization [109].

Beyond the specificity of each antidiabetic drug class, several studies have tested the effects of tight glycaemic control (HbA1c targets $<6.0-6.5 \%$ ) compared with standard care on major CV events and, to a lesser extent, on HF in T2D patients [110-112]. Sample populations of the Action to Control Cardiovascular Risk in Diabetes (ACCORD), Action in Diabetes and Vascular Disease: Preterax and Diamicron MR Controlled Evaluation (ADVANCE) and Veterans Affairs Diabetes Trial (VADT) were comparable, comprising relatively elderly T2D patients at high or very high CV risk and with diabetes of long duration. Yet, the results of these studies were rather surprising as they consistently demonstrated that tight glycaemic control failed to reduce HF outcomes, and even increased total mortality (in the ACCORD study) [110]. In fact, the lack of correlation between intensive glycaemic control and HF incidence reduction had already been described in the historical United Kingdom Prospective Diabetes Study (UKPDS) and further confirmed by two meta-analyses [113,114].

Since the change in US Food and Drug Administration (FDA) regulatory rules in 2008, more than 10 CV safety outcomes trials have been published for glucagon-like peptide-1 receptor agonists (GLP1RAs), dipeptidyl peptidase-4 inhibitors (DPP-4is), SGLT2is and insulin analogues [115-123]. However, whatever the study duration or the achieved differences in HbA1c between study arms, improvement of glucose control did not result in reduced HF incidences in most trials, and there was even a slight increase in HF hospitalizations (in the SAVOR trial with saxagliptin; Table I). Recently, the Liraglutide Effect and Action in Diabetes: Evaluation of Cardiovascular Outcome Results 
(LEADER) and Trial to Evaluate Cardiovascular and Other Long-term Outcomes with Semaglutide in Subjects with Type 2 Diabetes (SUSTAIN-6) revealed that both GLP-1RAs lowered rates of major adverse CV events in patients with T2D, but had no beneficial effects for HF reduction [119]. Likewise, both the FIGHT and LIVE trials concluded that liraglutide did not improve HF [124, 125]. Moreover, a large UK cohort confirmed a decrease in CV deaths without HF reduction while highlighting potential effects on atherosclerosis [126].

Two other recent studies have also delivered impressive results for glucose-lowering agents in HF: the Empagliflozin, Cardiovascular Outcomes, and Mortality in Type 2 Diabetes (EMPA-REG OUTCOME) trial and Canagliflozin Cardiovascular Assessment Study (CANVAS) assessed the effects of the two SGLT2is in patients with T2D and high CV risk [122,123]. These were the first studies to report significant HF reductions with antidiabetic treatments, while the benefits of this drug class for HF reduction were recently reinforced by a large-scale real-world observational study, which demonstrated an approximately $40 \%$ reduction of HF hospitalizations in a cohort of > 150,000 patients newly starting SGLT2is $v s$ other glucose-lowering drugs [127]. Of note, this real-life study recruited T2D patients following secondary and primary CV preventative regimes, and found similar HF reductions in both subgroups. Such protective effects were considered significant enough by companies developing SGLT2is to implement studies in patients with HF without diabetes. On the other hand, a mouse model of diabetic cardiomyopathy showed that cardiac dysfunction was associated with increased O-GlcNAcylation, which was corrected by hypoglycaemic SGLT2i treatment in the absence of lipotoxic hallmarks or other signs of glucose overload. This supports the notion that SGLT2is act at least partially through glucose-lowering effects [74].

Nevertheless, the discrepancy observed between the effects of SGLT2is and other glucose-lowering drugs on HF remains largely unexplained, although various hypotheses have been proposed in reviews and editorials. First, it should be borne in mind that SGLT2is lower glucose, but are not insulin sensitizers, suggesting they are not likely to massively increase cardiac glucose uptake. In addition, some authors have raised the possibility that the CV benefits of SGLT2is are independent of their glucose-lowering effects through several putative mechanisms [128]. In support of this glucoseindependent hypothesis, further analysis of the EMPA-REG OUTCOME trial recently found that the most important mediator of $\mathrm{CV}$ death risk reduction with empagliflozin is the change in haematocrit even before changes in HbA1c levels from fasting plasma glucose tests [129]. Second, the persistent glycosuria, along with a possible direct effect of SGLT2is on pancreatic islet alpha cells, decreases the insulin/glucagon ratio and leads to overproduction of ketone bodies, which are more efficient energy substrates for heart metabolism [130]. Glycosuria also mediates a uricosuric effect that might reduce the CV and HF risk classically correlated with plasma uric acid levels [131]. Body weight reduction associated with glycosuria could also play a part in overall $\mathrm{CV}$ risk reduction. Third, the natriuretic effects of SGLT2is induce a reduction of plasma volume and blood pressure, resulting in lower myocardial preloads and afterloads, respectively [132]. Reduced sodium-glucose proximal tubule 
reabsorption is also associated with increased kidney erythropoietin production, leading to increased haematocrit and enhanced myocardial oxygen delivery [133]. In addition, reduction of intraglomerular pressure and albuminuria with preservation of glomerular filtration rate (GFR) might be of particular importance in HF patients to avoid volume overload, and could also participate in the CV protection observed with SGLT2is [134]. Further preclinical and metabolic studies are now needed to determine whether SGLT2is are the first class of glucose-lowering agents to reduce HF by either reducing glucose overload or, alternatively, through class-specific effects, or both complementary mechanisms.

\section{CONCLUSION}

T2D is a major risk factor for HF and epidemiological data have, for decades, supported the idea that hyperglycaemia is strongly associated with diastolic dysfunction in diabetes patients. Mechanistic and animal studies have also confirmed what epidemiological observations have suggested: glucose overload is toxic to the heart. In the setting of diabetes, the heart loses its metabolic flexibility while glucose oxidation is suppressed. Glucose accumulation promotes ROS production, AGE accumulation and increased levels of O-GlcNAcylated protein. These hallmarks have been associated with decreased cardiac contractility, calcium signalling alterations and mitochondrial dysfunction. Yet, even though the exact contribution of each of these three pathways is still not clear, pharmacological and genetic interventions to limit their activation in diabetic mouse models have improved heart function. Recently, it was also found that SGLT2i treatments, which reduce hyperglycaemia by promoting urinary glucose excretion, decrease $\mathrm{CV}$ events in patients and improve cardiac phenotypes in rodent models, with some of these treatment benefits being most likely independent of hypoglycaemic effects. Taken as a whole, this large body of evidence confirms that glucotoxicity is central to diabetic cardiomyopathy and that glycaemic control is the primary goal in reducing HF prevalence in T2D patients. Specifically, chronic activation of the HBP is a key trigger of cardiac dysfunction and, in future, may well be a therapeutic target of interest in T2D-associated cardiomyopathy. 


\section{References}

[1] NCD Risk Factor Collaboration (NCD-RisC), Worldwide trends in diabetes since 1980: a pooled analysis of 751 population-based studies with 4.4 million participants. Lancet 2016; 387: 1513-30.

[2] Global Burden of Metabolic Risk Factors for Chronic Diseases Collaboration, Cardiovascular disease, chronic kidney disease, and diabetes mortality burden of cardiometabolic risk factors from 1980 to 2010: a comparative risk assessment. Lancet Diabetes Endocrinol 2014; 2: 634-47.

[3] Gregg EW, Gu Q, Cheng YJ, Narayan KM, Cowie CC. Mortality trends in men and women with diabetes, 1971 to 2000. Ann Intern Med 2007; 147: 149-55.

[4] Franjic B, Marwick TH. The diabetic, hypertensive heart: epidemiology and mechanisms of a very high-risk situation. J Hum Hypertens 2009; 23: 709-17.

[5] Nichols GA, Gullion CM, Koro CE, Ephross SA, Brown JB. The incidence of congestive heart failure in type 2 diabetes: an update. Diabetes Care 2004; 27: 1879-84.

[6] Norhammar A, Bodegård J, Nyström T, Thuresson M, Eriksson JW, Nathanson D. Incidence, prevalence and mortality of type 2 diabetes requiring glucose-lowering treatment, and associated risks of cardiovascular complications: a nationwide study in Sweden, 2006-2013. Diabetologia 2016; 59: $1692-701$.

[7] Clark AL, Cherif M, McDonagh TA, Squire IB. In-hospital worsening heart failure: a clinically relevant endpoint? ESC Heart Fail 2018; 5: 9-18.

[8] Nichols GA, Hillier TA, Erbey JR, Brown JB. Congestive heart failure in type 2 diabetes: prevalence, incidence, and risk factors. Diabetes Care 2001; 24: 1614-9.

[9] Low Wang CC, Hess CN, Hiatt WR, Goldfine AB. Clinical Update: Cardiovascular Disease in Diabetes Mellitus: Atherosclerotic Cardiovascular Disease and Heart Failure in Type 2 Diabetes Mellitus - Mechanisms, Management, and Clinical Considerations. Circulation 2016; 133: 2459-502. [10] Rubler S, Dlugash J, Yuceoglu YZ, Kumral T, Branwood AW, Grishman A. New type of cardiomyopathy associated with diabetic glomerulosclerosis. Am J Cardiol 1972; 30: 595-602.

[11] Regan TJ, Lyons MM, Ahmed SS, Levinson GE, Oldewurtel HA, Ahmad MR et al. Evidence for cardiomyopathy in familial diabetes mellitus. J Clin Invest 1977; 60: 884-99.

[12] van Hoeven KH, Factor SM. A comparison of the pathological spectrum of hypertensive, diabetic, and hypertensive-diabetic heart disease. Circulation 1990; 82: 848-55.

[13] Goldin A, Beckman JA, Schmidt AM, Creager MA. Advanced glycation end products: sparking the development of diabetic vascular injury. Circulation 2006; 114: 597-605.

[14] Factor SM, Minase T, Sonnenblick EH. Clinical and morphological features of human hypertensive-diabetic cardiomyopathy. Am Heart J 1980; 99: 446-58.

[15] Fischer VW, Barner HB, Larose LS. Pathomorphologic aspects of muscular tissue in diabetes mellitus. Hum Pathol 1984; 15: 1127-36.

[16] Seferović PM, Paulus WJ. Clinical diabetic cardiomyopathy: a two-faced disease with restrictive and dilated phenotypes. Eur Heart J 2015; 36: 1718-27, 1727a-1727c. 
[17] Paulus WJ, Tschöpe C, Sanderson JE, Rusconi C, Flachskampf FA, Rademakers FE et al. How to diagnose diastolic heart failure: a consensus statement on the diagnosis of heart failure with normal left ventricular ejection fraction by the Heart Failure and Echocardiography Associations of the European Society of Cardiology. Eur Heart J 2007; 28: 2539-50.

[18] Gonzalez JA, Kramer CM. Role of Imaging Techniques for Diagnosis, Prognosis and Management of Heart Failure Patients: Cardiac Magnetic Resonance. Curr Heart Fail Rep 2015; 12: 276-83.

[19] Khan JN, Wilmot EG, Leggate M, Singh A, Yates T, Nimmo M, et al. Subclinical diastolic dysfunction in young adults with Type 2 diabetes mellitus: a multiparametric contrast-enhanced cardiovascular magnetic resonance pilot study assessing potential mechanisms. Eur Heart $\mathbf{J}$ Cardiovasc Imaging 2014; 15: 1263-9.

[20] Redfield MM, Jacobsen SJ, Burnett JC, Mahoney DW, Bailey KR, Rodeheffer RJ. Burden of systolic and diastolic ventricular dysfunction in the community: appreciating the scope of the heart failure epidemic. JAMA 2003; 289: 194-202.

[21] Doehner W, Rauchhaus M, Ponikowski P, Godsland IF, von Haehling S, Okonko DO, et al. Impaired insulin sensitivity as an independent risk factor for mortality in patients with stable chronic heart failure. J Am Coll Cardiol 2005; 46: 1019-26.

[22] Dauriz M, Targher G, Laroche C, Temporelli PL, Ferrari R, Anker S, et al. ESC-HFA Heart Failure Long-Term Registry, Association Between Diabetes and 1-Year Adverse Clinical Outcomes in a Multinational Cohort of Ambulatory Patients with Chronic Heart Failure: Results From the ESCHFA Heart Failure Long-Term Registry. Diabetes Care 2017; 40: 671-78.

[23] Zhang L, Liebelt JJ, Madan N, Shan J, Taub CC. Comparison of Predictors of Heart Failure ith Preserved Versus Reduced Ejection Fraction in a Multiracial Cohort of Preclinical Left Ventricular Diastolic Dysfunction. Am J Cardiol 2017; 119: 1815-20.

[24] Itzhaki Ben Zadok O, Kornowski R, Goldenberg I, Klempfner R, Toledano Y, Biton Y, et al. Admission blood glucose and 10-year mortality among patients with or without pre-existing diabetes mellitus hospitalized with heart failure. Cardiovasc Diabetol 2017; 16: 102.

[25] Bertoni AG, Hundley WG, Massing MW, Bonds DE, Burke GL, Goff DC. Heart failure prevalence, incidence, and mortality in the elderly with diabetes. Diabetes Care 2004; 27: 699-703.

[26] MacDonald MR, Petrie MC, Varyani F, Ostergren J, Michelson EL, Young JB, et al. Impact of diabetes on outcomes in patients with low and preserved ejection fraction heart failure: an analysis of the Candesartan in Heart failure: Assessment of Reduction in Mortality and morbidity (CHARM) programme. Eur Heart J 2008; 29: 1377-85.

[27] Holland DJ, Marwick TH, Haluska BA, Leano R, Hordern MD, Hare JL, et al. Subclinical LV dysfunction and 10-year outcomes in type 2 diabetes mellitus. Heart 2015; 101: 1061-6.

[28] Iribarren C, Karter AJ, Go AS, Ferrara A, Liu JY, Sidney S, et al. Glycemic control and heart failure among adult patients with diabetes. Circulation 2001; 103: 2668-73. 
[29] Erqou S, Lee CT, Suffoletto M, Echouffo-Tcheugui JB, de Boer RA, van Melle JP, et al. Association between glycated haemoglobin and the risk of congestive heart failure in diabetes mellitus: systematic review and meta-analysis. Eur J Heart Fail 2013; 15: 185-93.

[30] Kristensen SL, Jhund PS, Mogensen UM, Rørth R, Abraham WT, Desai A, et al. PARADIGMHF and ATMOSPHERE Committees and Investigators, Prognostic Value of N-Terminal Pro-B-Type Natriuretic Peptide Levels in Heart Failure Patients with and Without Atrial Fibrillation. Circ Heart Fail 2017; 10: pii: e004409.

[31] Gerstein HC, Miller ME, Byington RP, Goff DC, Bigger JT, Buse JB, Cushman WC, et al. Effects of intensive glucose lowering in type 2 diabetes. N Engl J Med 2008; 358: 2545-59.

[32] Aguilar H, Fricovsky E, Ihm S, Schimke M, Maya-RamosL, Aroonsakool N, et al. Role for highglucose-induced protein O-GlcNAcylation in stimulating cardiac fibroblast collagen synthesis. Am J Physiol Cell Physiol 2014; 306: C794-804.

[33] Elder DH, Singh JS, Levin D, Donnelly LA, Choy AM, George J, et al. Mean HbA1c and mortality in diabetic individuals with heart failure: a population cohort study. Eur J Heart Fail 2016; 18: 94-102.

[34] Guy J, Ogden L, Wadwa RP, Hamman RF, Mayer-Davis EJ, Liese AD, et al. Lipid and lipoprotein profiles in youth with and without type 1 diabetes: the SEARCH for Diabetes in Youth case-control study. Diabetes Care 2009; 32: 416-20.

[35] Cusi K, Sanyal AJ, Zhang S, Hartman ML, Bue-Valleskey JM, Hoogwerf BJ, et al. Non-alcoholic fatty liver disease (NAFLD) prevalence and its metabolic associations in patients with type 1 diabetes and type 2 diabetes. Diabetes Obes Metab 2017; 19: 1630-4.

[36] Ritchie RH, Zerenturk EJ, Prakoso D, Calkin AC. Lipid metabolism and its implications for type 1 diabetes-associated cardiomyopathy. J Mol Endocrinol 2017; 58: R225-40.

[37] Rosengren A, Vestberg D, Svensson AM, Kosiborod M, Clements M, Rawshani A, et al. Longterm excess risk of heart failure in people with type 1 diabetes: a prospective case-control study. Lancet Diabetes Endocrinol 2015; 3: 876-85.

[38] Raev DC. Which left ventricular function is impaired earlier in the evolution of diabetic cardiomyopathy? An echocardiographic study of young type I diabetic patients. Diabetes Care 1994; 17: 633-9.

[39] Berková M, Opavský J, Berka Z, Skranka V, Salinger J. Left ventricular diastolic filling in young persons with type 1 diabetes mellitus. Biomed Pap Med Fac Univ Palacky Olomouc Czech Repub 2003; 147: 57-61.

[40] Labombarda F, Leport M, Morello R, Ribault V, Kauffman D, Brouard J, et al. Longitudinal left ventricular strain impairment in type 1 diabetes children and adolescents: a 2D speckle strain imaging study. Diabetes Metab 2014; 40: 292-8. 
[41] Fiorina P, La Rocca E, Astorri E, Lucignani G, Rossetti C, Fazio F, et al. Reversal of left ventricular diastolic dysfunction after kidney-pancreas transplantation in type 1 diabetic uremic patients. Diabetes Care 2000; 23: 1804-10.

[42] Wong TC, Piehler KM, Kang IA, Kadakkal A, Kellman P, Schwartzman DS, et al. Myocardial extracellular volume fraction quantified by cardiovascular magnetic resonance is increased in diabetes and associated with mortality and incident heart failure admission. Eur Heart J 2014; 35: 657-64.

[43] Grothues F, Smith GC, Moon JC, Bellenger NG, Collins P, Klein HU, et al. Comparison of interstudy reproducibility of cardiovascular magnetic resonance with two-dimensional echocardiography in normal subjects and in patients with heart failure or left ventricular hypertrophy. Am J Cardiol 2002; 90: 29-34.

[44] Joubert M, Tager P, Legallois D, Defourneaux E, Le Guellec B, Gerber B, et al. Test-retest reproducibility of cardiac magnetic resonance imaging in healthy mice at 7-Tesla: effect of anesthetic procedures. Sci Rep 2017; 7: 6698.

[45] Cao Y, Zeng W, Cui Y, Kong X, Wang M, Yu J, et al. Increased myocardial extracellular volume assessed by cardiovascular magnetic resonance T1 mapping and its determinants in type 2 diabetes mellitus patients with normal myocardial systolic strain. Cardiovasc Diabetol 2018; 17 : 7.

[46] Poirier P, Bogaty P, Garneau C, Marois L, Dumesnil JG. Diastolic dysfunction in normotensive men with well-controlled type 2 diabetes: importance of manoeuvres in echocardiographic screening for preclinical diabetic cardiomyopathy. Diabetes Care 2001; 24: 5-10.

[47] Boyer JK, Thanigaraj S, Schechtman KB, Pérez JE. Prevalence of ventricular diastolic dysfunction in asymptomatic, normotensive patients with diabetes mellitus. Am J Cardiol 2004; 93: $870-5$.

[48] Ernande L, Audureau E, Jellis CL, Bergerot C, Henegar C, Sawaki D, et al. Clinical Implications of Echocardiographic Phenotypes of Patients with Diabetes Mellitus. J Am Coll Cardiol 2017; 70: 1704-16.

[49] Ernande L, Bergerot C, Girerd N, Thibault H, Davidsen ES, Gautier Pignon-Blanc P, et al. Longitudinal myocardial strain alteration is associated with left ventricular remodeling in asymptomatic patients with type 2 diabetes mellitus. J Am Soc Echocardiogr 2014; 27: 479-88.

[50] Liu JH, Chen Y, Yuen M, Zhen Z, Chan CW, Lam KS, Het al. Incremental prognostic value of global longitudinal strain in patients with type 2 diabetes mellitus. Cardiovasc Diabetol 2016; 15: 22.

[51] Di Pino A, Mangiafico S, Urbano F, Scicali R, Scandura S, d'Agate V, et al. HbA1c Identifies Subjects with Prediabetes and Subclinical Left Ventricular Diastolic Dysfunction. J Clin Endocrinol Metab 2017; 102: 3756-64.

[52] Leung M, Wong VW, Hudson M, Leung DY. Impact of Improved Glycemic Control on Cardiac Function in Type 2 Diabetes Mellitus. Circ Cardiovasc Imaging 2016; 9: e003643.

[53] Rijzewijk LJ, van der Meer RW, Lamb HJ, de Jong HW, Lubberink M, Romijn JA, et al. Altered myocardial substrate metabolism and decreased diastolic function in nonischemic human diabetic 
cardiomyopathy: studies with cardiac positron emission tomography and magnetic resonance imaging. J Am Coll Cardiol 2009; 54: 1524-32.

[54] Pascual F, Coleman RA. Fuel availability and fate in cardiac metabolism: A tale of two substrates. Biochim Biophys Acta 2016; 1861: 1425-33.

[55] Bertrand L, Horman S, Beauloye C, Vanoverschelde JL. Insulin signalling in the heart. Cardiovasc Res 2008; 79: 238-48.

[56] Mazumder PK, O'Neill BT, Roberts MW, Buchanan J, Yun UJ, Cooksey RC. et al. Impaired cardiac efficiency and increased fatty acid oxidation in insulin-resistant ob/ob mouse hearts. Diabetes 2004; 53: 2366-74.

[57] Taegtmeyer H, McNulty P, Young ME. Adaptation and maladaptation of the heart in diabetes: Part I: general concepts. Circulation 2002; 105: 1727-33.

[58] Young ME, McNulty P, Taegtmeyer H. Adaptation and maladaptation of the heart in diabetes: Part II: potential mechanisms. Circulation 2002; 105: 1861-70.

[59] Rodrigues B, Cam MC, McNeill JH. Myocardial substrate metabolism: implications for diabetic cardiomyopathy. J Mol Cell Cardiol 1995; 27: 169-79.

[60] Bugger H, Boudina S, Hu XX, Tuinei J, Zaha VG, Theobald HA, et al. Type 1 diabetic akita mouse hearts are insulin sensitive but manifest structurally abnormal mitochondria that remain coupled despite increased uncoupling protein 3. Diabetes 2008; 57: 2924-32.

[61] Hafstad AD, Solevåg GH, Severson DL, Larsen TS, Aasum E. Perfused hearts from Type 2 diabetic (db/db) mice show metabolic responsiveness to insulin. Am J Physiol Heart Circ Physiol 2006; 290: H1763-9.

[62] Shoghi KI, Gropler RJ, Sharp T, Herrero P, Fettig N, Su Y, et al. Time course of alterations in myocardial glucose utilization in the Zucker diabetic fatty rat with correlation to gene expression of glucose transporters: a small-animal PET investigation. J Nucl Med 2008; 49: 1320-7.

[63] Welch MJ, Lewis JS, Kim J, Sharp TL, Dence CS, Gropler RJ, et al. Assessment of myocardial metabolism in diabetic rats using small-animal PET: a feasibility study. J Nucl Med 2006; 47: 689-97. [64] van den Brom CE, Huisman MC, Vlasblom R, Boontje NM, Duijst S, Lubberink M, et al. Altered myocardial substrate metabolism is associated with myocardial dysfunction in early diabetic cardiomyopathy in rats: studies using positron emission tomography. Cardiovasc Diabetol 2009; 8: 39. [65] Ménard SL, Croteau E, Sarrhini O, Gélinas R, Brassard P, Ouellet R, et al. Abnormal in vivo myocardial energy substrate uptake in diet-induced type 2 diabetic cardiomyopathy in rats. Am $\mathbf{J}$ Physiol Endocrinol Metab 2010; 298: E1049-57.

[66] Gupte AA, Minze LJ, Reyes M, Ren Y, Wang W, Brunner G, et al. High-fat feeding-induced hyperinsulinemia increases cardiac glucose uptake and mitochondrial function despite peripheral insulin resistance. Endocrinology 2013; 154: 2650-62. 
[67] Joubert M, Jagu B, Montaigne D, Marechal X, Tesse A, Ayer A, et al. The SGLT2 Inhibitor Dapagliflozin Prevents Cardiomyopathy in a Diabetic Lipodystrophic Mouse Model. Diabetes 2017; 66:1030-40.

[68] Thorn SL, de Kemp RA, Dumouchel T, Klein R, Renaud JM, Wells RG, et al. Repeatable noninvasive measurement of mouse myocardial glucose uptake with 18F-FDG: evaluation of tracer kinetics in a type 1 diabetes model. J Nucl Med 2013; 54: 1637-44.

[69] Kaneta T, Hakamatsuka T, Takanami K, Yamada T, Takase K, Sato A, et al. Evaluation of the relationship between physiological FDG uptake in the heart and age, blood glucose level, fasting period, and hospitalization. Ann Nucl Med 2006; 20: 203-8.

[70] Chatham JC, Seymour AM. Cardiac carbohydrate metabolism in Zucker diabetic fatty rats. Cardiovasc Res 2002; 55: 104-12.

[71] Le Page LM, Rider OJ, Lewis AJ, Ball V, Clarke K, Johansson E, et al. Increasing Pyruvate Dehydrogenase Flux as a Treatment for Diabetic Cardiomyopathy: A Combined 13C Hyperpolarized Magnetic Resonance and Echocardiography Study. Diabetes 2015; 64: 2735-43.

[72] Taegtmeyer H, Beauloye C, Harmancey R, Hue L. Insulin resistance protects the heart from fuel overload in dysregulated metabolic states. Am J Physiol Heart Circ Physiol 2013; 305: H1693-7.

[73] Montaigne D, Marechal X, Coisne A, Debry N, Modine T, Fayad G, et al. Myocardial contractile dysfunction is associated with impaired mitochondrial function and dynamics in type 2 diabetic but not in obese patients. Circulation 2014; 130: 554-64.

[74] Joubert M, Jagu B, Montaigne D, Marechal X, Tesse A, Ayer A, et al. The Sodium-Glucose Cotransporter 2 Inhibitor Dapagliflozin Prevents Cardiomyopathy in a Diabetic Lipodystrophic Mouse Model. Diabetes 2017; 66: 1030-40.

[75] Habibi J, Aroor AR, Sowers JR, Jia G, Hayden MR, Garro M, et al. Sodium glucose transporter 2 (SGLT2) inhibition with empagliflozin improves cardiac diastolic function in a female rodent model of diabetes. Cardiovasc Diabetol 2017; 16: 9.

[76] Cai L, Li W, Wang G, Guo L, Jiang Y, Kang YJ. Hyperglycemia-induced apoptosis in mouse myocardium: mitochondrial cytochrome C-mediated caspase-3 activation pathway. Diabetes 2002; 51: 1938-48.

[77] Sen S, Kundu BK, Wu HC, Hashmi SS, Guthrie P, Locke LW, et al. Glucose regulation of loadinduced mTOR signaling and ER stress in mammalian heart. J Am Heart Assoc 2013; 2: e004796.

[78] Dyntar D, Sergeev P, Klisic J, Ambühl P, Schaub MC, Donath MY. High glucose alters cardiomyocyte contacts and inhibits myofibrillar formation. J Clin Endocrinol Metab 2006; 91: 1961-7. [79] Giacco F, BrownleeM. Oxidative stress and diabetic complications. Circ Res 2010; 107: 1058-70. [80] Fiordaliso F, Bianchi R, Staszewsky L, Cuccovillo I, Doni M, Laragione T, et al. Antioxidant treatment attenuates hyperglycemia-induced cardiomyocyte death in rats. J Mol Cell Cardiol 2004; 37: $959-68$ 
[81] MacCarthy PA, Grieve DJ, Li LM, Dunster C, Kelly FJ, Shah MA. Impaired endothelial regulation of ventricular relaxation in cardiac hypertrophy: role of reactive oxygen species and NADPH oxidase. Circulation 2001; 104: 2967-74.

[82] Bendall JK, Damy T, Ratajczak P, Loyer X, Monceau V, MartyI, et al. Role of myocardial neuronal nitric oxide synthase-derived nitric oxide in beta-adrenergic hyporesponsiveness after myocardial infarction-induced heart failure in rat. Circulation 2004; 110: 2368-75.

[83] Heymes C, Bendall JK, Ratajczak P, Cave AC, Samuel JL, Hasenfuss G, et al. Increased myocardial NADPH oxidase activity in human heart failure. J Am Coll Cardiol 2003; 41: 2164-71.

[84] Kolwicz SC, Tian R. Glucose metabolism and cardiac hypertrophy. Cardiovasc Res 2011; 90: 194-201.

[85] Li SY, Yang X, Ceylan-Isik AF, Du M, Sreejayan N, Ren J. Cardiac contractile dysfunction in Lep/Lep obesity is accompanied by NADPH oxidase activation, oxidative modification of sarco(endo)plasmic reticulum Ca2+-ATPase and myosin heavy chain isozyme switch. Diabetologia 2006; 49: 1434-46.

[86] Serpillon S, Floyd BC, Gupte RS, George S, Kozicky M, Neito V, et al. Superoxide production by $\mathrm{NAD}(\mathrm{P}) \mathrm{H}$ oxidase and mitochondria is increased in genetically obese and hyperglycemic rat heart and aorta before the development of cardiac dysfunction. The role of glucose-6-phosphate dehydrogenase-derived NADPH. Am J Physiol Heart Circ Physiol 2009; 297: H153-62.

[87] Li Y, Feng Q, Arnold M, Peng T. Calpain activation contributes to hyperglycaemia-induced apoptosis in cardiomyocytes. Cardiovasc Res 2009; 84: 100-10.

[88] Balteau M, Tajeddine N, de Meester C, Ginion A, des Rosiers C, Brady NR, et al. NADPH oxidase activation by hyperglycaemia in cardiomyocytes is independent of glucose metabolism but requires SGLT1. Cardiovasc Res 2011; 92: 237-46.

[89] Van Steenbergen A, Balteau M, Ginion A, Ferté L, Battault S, Ravenstein CM, et al. Sodiummyoinositol cotransporter-1, SMIT1, mediates the production of reactive oxygen species induced by hyperglycemia in the heart. Sci Rep 2017; 8: 41166.

[90] Shah MS, Brownlee M. Molecular and Cellular Mechanisms of Cardiovascular Disorders in Diabetes. Circ Res 2016; 118: 1808-29.

[91] Ma H, Li SY, Xu P, Babcock SA, Dolence EK, Brownlee M, et al. Advanced glycation endproduct (AGE) accumulation and AGE receptor (RAGE) up-regulation contribute to the onset of diabetic cardiomyopathy. J Cell Mol Med 2009; 13: 1751-64.

[92] Shao CH, Tian C, Ouyang S, Moore CJ, Alomar F, Nemet I, et al. Carbonylation induces heterogeneity in cardiac ryanodine receptor function in diabetes mellitus. Mol Pharmacol 2012; 82: 383-99.

[93] Tian C, Alomar F, Moore CJ, Shao CH, Kutty S, Singh J, et al. Reactive carbonyl species and their roles in sarcoplasmic reticulum Ca2+ cycling defect in the diabetic heart. Heart Fail Rev 2014; 19: 101-12. 
[94] Clark RJ, McDonough PM, Swanson E, Trost SU, Suzuki M, Fukuda M, et al. Diabetes and the accompanying hyperglycemia impairs cardiomyocyte calcium cycling through increased nuclear OGlcNAcylation. J Biol Chem 2003; 278: 44230-7.

[95] Hu Y, Belke D, Suarez J, Swanson E, Clark R, Hoshijima M, et al. Adenovirus-mediated overexpression of O-GlcNAcase improves contractile function in the diabetic heart. Circ Res 2005; 96: 1006-13.

[96] Fricovsky ES, Suarez J, Ihm SH, Scott BT, Suarez-Ramirez JA, Banerjee I, et al. Excess protein O-GlcNAcylation and the progression of diabetic cardiomyopathy. Am J Physiol Regul Integr Comp Physiol 2012; 303: R689-99.

[97] Yokoe S, Asahi M, Takeda T, Otsu K, Taniguchi N, Miyoshi E, et al. Inhibition of phospholamban phosphorylation by O-GlcNAcylation: implications for diabetic cardiomyopathy. Glycobiology 2010; 20: 1217-26.

[98] Erickson JR, Pereira L, Wang L, Han G, Ferguson A, Dao K, et al. Diabetic hyperglycaemia activates CaMKII and arrhythmias by O-linked glycosylation. Nature 2013; 502: 372-6.

[99] Ramirez-Correa GA, Ma J, Slawson C, Zeidan Q, Lugo-Fagundo NS, Xu M, et al. Removal of Abnormal Myofilament O-GlcNAcylation Restores Ca2+ Sensitivity in Diabetic Cardiac Muscle. Diabetes 2015; 64: 3573-87.

[100] Hu Y, Suarez J, Fricovsky E, Wang H, Scott BT, Trauger SA, et al. Increased enzymatic OGlcNAcylation of mitochondrial proteins impairs mitochondrial function in cardiac myocytes exposed to high glucose. J Biol Chem 2009; 284: 547-55.

[101] Banerjee PS, Ma J, Hart GW. Diabetes-associated dysregulation of O-GlcNAcylation in rat cardiac mitochondria. Proc Natl Acad Sci U S A 2015; 112: 6050-5.

[102] Marsh SA, Dell'Italia LJ, Chatham JC. Activation of the hexosamine biosynthesis pathway and protein O-GlcNAcylation modulate hypertrophic and cell signaling pathways in cardiomyocytes from diabetic mice. Amino Acids 2011; 40: 819-28.

[103] Facundo HT, Brainard RE, Watson LJ, Ngoh GA, Hamid T, Prabhu SD, et al. GlcNAc signaling is essential for NFAT-mediated transcriptional reprogramming during cardiomyocyte hypertrophy. Am J Physiol Heart Circ Physiol 2012; 302: H2122-30.

[104] Stades MA, Heikens JT, Erkelens DW, Holleman F, Hoekstra JB. Metformin and lactic acidosis: cause or coincidence? A review of case reports. J Intern Med 2004; 255: 179-87.

[105] Eurich DT, Weir DL, Majumdar SR, Tsuyuki RT, Johnson JA, Tjosvold L, et al. Comparative safety and effectiveness of metformin in patients with diabetes mellitus and heart failure: systematic review of observational studies involving 34,000 patients. Circ Heart Fail 2013; 6: 395-402.

[106] Ruiter R, Visser LE, van Herk-Sukel MP, Geelhoed-Duijvestijn PH, de Bie S, Straus SM, et al. Prescribing of rosiglitazone and pioglitazone following safety signals: analysis of trends in dispensing patterns in the Netherlands from 1998 to 2008. Drug Saf 2012; 35: 471-80. 
[107] Gilbert RE, Krum H. Heart failure in diabetes: effects of anti-hyperglycaemic drug therapy. Lancet 2015; 385: 2107-17.

[108] Komajda M, McMurray JJ, Beck-Nielsen H, Gomis R, Hanefeld M, Pocock SJ, et al. Heart failure events with rosiglitazone in type 2 diabetes: data from the RECORD clinical trial. Eur Heart $\mathbf{J}$ 2010; 31: 824-31.

[109] Young LH, Viscoli CM, Schwartz GG, Inzucchi SE, Curtis JP, Gorman MJ, et al. Heart Failure After Ischemic Stroke or TIA in Insulin-Resistant Patients Without Diabetes Treated with Pioglitazone. Circulation 2018 [Epub ahead of print].

[110] Gerstein HC, Miller ME, Byington RP, Goff DC, Bigger JT, Buse JB, et al. Effects of intensive glucose lowering in type 2 diabetes. N Engl J Med 2008; 358: 2545-59.

[111] Patel A, MacMahon S, Chalmers J, Neal B, Billot L, Woodward M, et al. Intensive blood glucose control and vascular outcomes in patients with type 2 diabetes. N Engl J Med 2008; 358: 2560-72.

[112] Duckworth D, Abraira C, Moritz T, Reda D, Emanuele N, Reaven PD, et al. Glucose control and vascular complications in veterans with type 2 diabetes. N Engl J Med 2009; 360: 129-39.

[113] Castagno D, Baird-Gunning J, Jhund PS, Biondi-Zoccai G, MacDonald MR, Petrie MC, et al. Intensive glycemic control has no impact on the risk of heart failure in type 2 diabetic patients: evidence from a 37,229 patient meta-analysis. Am Heart J 2011; 162: 938-48.e2.

[114] Roussel R, Steg PG, Mohammedi K, Marre M, Potier L. Prevention of cardiovascular disease through reduction of glycaemic exposure in type 2 diabetes: A perspective on glucose-lowering interventions. Diabetes Obes Metab 2018; 20: 238-44.

[115] Scirica BM, Bhatt DL, Braunwald E, Steg PG, Davidson J, Hirshberg B, et al. Saxagliptin and cardiovascular outcomes in patients with type 2 diabetes mellitus. N Engl J Med 2013; 369: 1317-26.

[116] White WB, Cannon CP, Heller SR, Nissen SE, Bergenstal RM, Bakris GL, et al. Alogliptin after acute coronary syndrome in patients with type 2 diabetes. N Engl J Med 2013; 369: 1327-35.

[117] Green JB, Bethel MA, Armstrong PW, Buse JB, Engel SS, Garg J, et al. Effect of Sitagliptin on Cardiovascular Outcomes in Type 2 Diabetes. N Engl J Med 2015; 373: 232-42.

[118] Pfeffer MA, Claggett B, Diaz R, Dickstein K, Gerstein HC, Køber LV, et al. Lixisenatide in Patients with Type 2 Diabetes and Acute Coronary Syndrome. N Engl J Med 2015; 373: 2247-57.

[119] Marso SP, Daniels GH, Brown-Frandsen K, Kristensen P, Mann JF, Nauck MA, et al. Liraglutide and Cardiovascular Outcomes in Type 2 Diabetes. N Engl J Med 2016; 375: 311-22.

[120] Holman RR, Bethel MA, Mentz RJ, Thompson VP, Lokhnygina Y, Buse JB, et al. Effects of Once-Weekly Exenatide on Cardiovascular Outcomes in Type 2 Diabetes. N Engl J Med 2017; 377: 1228-39.

[121] Gerstein HC, Bosch J, Dagenais GR, Díaz R, Jung H, Maggioni AP, et al., Basal insulin and cardiovascular and other outcomes in dysglycemia. N Engl J Med 2012; 367: 319-28. 
[122] Zinman B, Wanner C, Lachin JM, Fitchett D, Bluhmki E, Hantel S et al. Empagliflozin, Cardiovascular Outcomes, and Mortality in Type 2 Diabetes. N Engl J Med 2015; 373: 2117-28.

[123] Neal B, Perkovic V, Mahaffey KW, de Zeeuw D, Fulcher G, Erondu N, et al. Canagliflozin and Cardiovascular and Renal Events in Type 2 Diabetes. N Engl J Med 2017; 377: 644-57.

[124] Jorsal A, Kistorp C, Holmager P, Tougaard RS, Nielsen R, Hänselmann A, et al. Effect of liraglutide, a glucagon-like peptide-1 analogue, on left ventricular function in stable chronic heart failure patients with and without diabetes (LIVE)-a multicentre, double-blind, randomised, placebocontrolled trial. Eur J Heart Fail 2017; 19: 69-77.

[125] Margulies KB, Hernandez AF, Redfield MM, Givertz MM, Oliveira GH, Cole R, et al. Effects of Liraglutide on Clinical Stability Among Patients with Advanced Heart Failure and Reduced Ejection Fraction: A Randomized Clinical Trial. JAMA 2016; 316: 500-8.

[126] Anyanwagu U, Mamza J, Donnelly R, Idris I. Effect of adding GLP-1RA on mortality, cardiovascular events, and metabolic outcomes among insulin-treated patients with type 2 diabetes: A large retrospective UK cohort study. Am Heart J 2018; 196: 18-27.

[127] Kosiborod M, Cavender MA, Fu AZ, Wilding JP, Khunti K, Holl RW, et al. Lower Risk of Heart Failure and Death in Patients Initiated on Sodium-Glucose Cotransporter-2 Inhibitors Versus Other Glucose-Lowering Drugs: The CVD-REAL Study (Comparative Effectiveness of Cardiovascular Outcomes in New Users of Sodium-Glucose Cotransporter-2 Inhibitors). Circulation 2017; 136: 249-59.

[128] Lytvyn Y, Bjornstad P, Udell JA, Lovshin JA, Cherney D. Sodium Glucose Cotransporter-2 Inhibition in Heart Failure: Potential Mechanisms, Clinical Applications, and Summary of Clinical Trials. Circulation 2017; 136: 1643-58.

[129] Inzucchi SE, Zinman B, Fitchett D, Wanner C, Ferrannini E, Schumacher M, et al. How Does Empagliflozin Reduce Cardiovascular Mortality? Insights from a Mediation Analysis of the EMPAREG OUTCOME Trial. Diabetes Care 2018; 41: 356-63.

[130] Ferrannini E, Mark M, Mayoux E. CV Protection in the EMPA-REG OUTCOME Trial: A "Thrifty Substrate" Hypothesis. Diabetes Care 2016; 39: 1108-14.

[131] Lytvyn Y, Škrtić M, Yang GK, Yip PM, Perkins BA, Cherney DZ. Glycosuria-mediated urinary uric acid excretion in patients with uncomplicated type 1 diabetes mellitus. Am J Physiol Renal Physiol 2015; 308: F77-83.

[132] Heerspink HJ, Perkins BA, Fitchett DH, Husain M, Cherney DZ. Sodium Glucose Cotransporter 2 Inhibitors in the Treatment of Diabetes Mellitus: Cardiovascular and Kidney Effects, Potential Mechanisms, and Clinical Applications. Circulation 2016; 134: 752-72.

[133] Martens P, Mathieu C, Verbrugge FH. Promise of SGLT2 Inhibitors in Heart Failure: Diabetes and Beyond. Curr Treat Options Cardiovasc Med 2017; 19: 23. 
[134] Cherney DZ, Perkins BA, Soleymanlou N, Maione M, Lai V, Lee A, et al. Renal hemodynamic effect of sodium-glucose cotransporter 2 inhibition in patients with type 1 diabetes mellitus. Circulation 2014; 129: 587-97. 


\section{Figure legend}

Fig. 1. Diabetic hearts display metabolic inflexibility, characterized by a decreased ability to utilize glucose as an energy substrate. Acetyl coenzyme A (acyl-CoA) and citrate accumulation, promoted by excessive fatty acid catabolism, inhibits glucose oxidation that, together with chronic hyperglycaemia, promotes glucose overload that, in turn, promotes three pathways: the pentose phosphate pathway; the hexosamine pathway; and glycation. Accumulation of the different products of these pathwaysexcess reactive oxygen species (ROS) production, chronic activation of hexosamine pathways and advanced glycation end-product (AGE) accumulation-leads to cardiac dysfunction. FFA: free fatty acid; NADPH: nicotinamide adenine dinucleotide phosphate hydrogen; 6-P: 6-phosphate; biP: bisphosphonate; O-GlcNAc: O-linked $\beta$-N-acetylglucosamine; OGT: O-GlcNAc transferase; OGA: OGlcNAcase; PDH: pyruvate dehydrogenase. 


\section{[Glucose]}

Figure 1

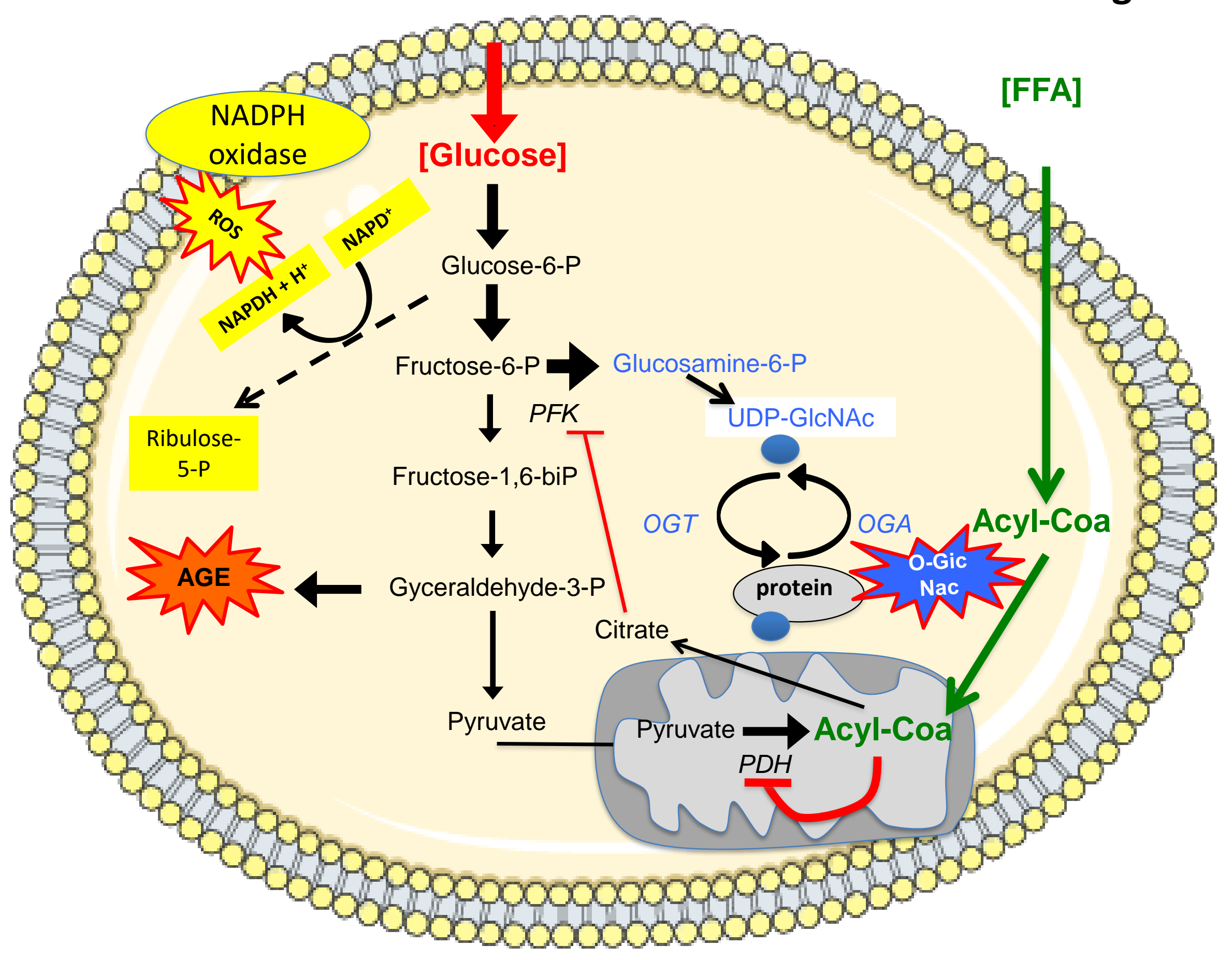


Table I

Main characteristics and heart failure (HF) outcomes in studies of intensive glucose control and cardiovascular (CVS) safety carried out over the past 20 years

\begin{tabular}{|c|c|c|c|c|c|c|c|}
\hline Trial & Study aim & Treatment & $\begin{array}{c}\text { Population } \\
(\text { n) }\end{array}$ & $\begin{array}{l}\text { Baseline HF } \\
(\%)\end{array}$ & $\begin{array}{c}\text { Median study } \\
\text { duration (years) }\end{array}$ & $\underset{(\%)}{\Delta \text { HbA1c }}$ & $\begin{array}{l}\text { HF outcome HR } \\
(95 \% \mathrm{CI})\end{array}$ \\
\hline UKPDS & Intensive glucose control & Diet, SU, MET, INS & 3867 & NA & 10 & 0.9 & $0.91(0.54-1.52)$ \\
\hline ACCORD & Intensive glucose control & Diet, MET, SU, TZD, INCR, INS & 10,251 & 5 & 3.5 & 1.1 & $1.18(0.93-1.49)$ \\
\hline ADVANCE & Intensive glucose control & Diet, MET, SU, TZD, AGI, INS & 11,140 & NA & 5 & 0.8 & $0.95(0.79-1.14)$ \\
\hline VADT & Intensive glucose control & Diet, MET, SU, TZD, INCR, AGI, INS & 1791 & NA & 5.6 & 1.5 & $0.91(0.67-1.25)$ \\
\hline SAVOR-TIMI & CVS safety of saxagliptin & Diet, MET, SU, TZD, INS, saxagliptin $^{\dagger}$ & 16,492 & 13 & 2.1 & 0.2 & $1.27(1.07-1.51)$ \\
\hline EXAMINE & CVS safety of alogliptin & Diet, MET, SU, TZD, INS, alogliptin ${ }^{\dagger}$ & 5380 & 28 & 1.5 & 0.4 & $1.07(0.79-1.46)$ \\
\hline TECOS & CVS safety of sitagliptin & Diet, MET, SU, TZD, INS, sitagliptin ${ }^{\dagger}$ & 14,671 & 18 & 3.0 & 0.3 & $1.00(0.83-1.20)$ \\
\hline ACE & CVS safety of acarbose & Diet, acarbose ${ }^{\dagger}$ & 6522 & NA & 5.0 & 0.1 & $0.89(0.63-1.24)$ \\
\hline ELIXA & $\begin{array}{l}\text { CVS safety of } \\
\text { lixisenatide }\end{array}$ & Diet, MET, SU, TZD, INS, lixisenatide $^{\dagger}$ & 6068 & 22 & 2.0 & 0.3 & $0.96(0.75-1.23)$ \\
\hline LEADER & CVS safety of liraglutide & $\begin{array}{l}\text { Diet, MET, SU, TZD, INCR, AGI, } \\
\text { SGLT2i, INS, liraglutide }\end{array}$ & 9340 & 14 & 3.8 & 0.4 & $0.87(0.73-1.05)$ \\
\hline SUSTAIN-6 & $\begin{array}{l}\text { CVS safety of } \\
\text { semaglutide }\end{array}$ & $\begin{array}{c}\text { Diet, MET, SU, TZD, AGI, INS, } \\
\text { semaglutide }^{\dagger}\end{array}$ & 3297 & 24 & 2.1 & 0.8 & $1.11(0.77-1.61)$ \\
\hline EXSCEL & $\begin{array}{l}\text { CVS safety of exenatide } \\
\text { LAR }\end{array}$ & $\begin{array}{l}\text { Diet, MET, SU, TZD, INCR, AGI, } \\
\text { SGLT2i, INS, exenatide LAR }\end{array}$ & 14,752 & 16 & 3.2 & 0.5 & $0.94(0.78-1.13)$ \\
\hline ORIGIN & CVS safety of glargine & $\begin{array}{c}\text { Diet, MET, SU, rapid-acting INS; } \\
\text { glargine }^{\dagger}\end{array}$ & 12,537 & NA & 6.2 & 0.3 & $0.90(0.77-1.05)$ \\
\hline EMPA-REG & $\begin{array}{l}\text { CVS safety of } \\
\text { empagliflozin }\end{array}$ & $\begin{array}{c}\text { Diet, MET, SU, TZD, INCR, INS, } \\
\text { empagliflozin }^{\dagger}\end{array}$ & 7020 & 10 & 3.1 & 0.3 & $0.65(0.50-0.85)$ \\
\hline CANVAS & $\begin{array}{l}\text { CVS safety of } \\
\text { canagliflozin }\end{array}$ & $\begin{array}{c}\text { Diet, MET, SU, INCR, INS, } \\
\text { canagliflozin }^{\dagger}\end{array}$ & 10,142 & 14 & 3.6 & 0.6 & $0.67(0.52-0.87)$ \\
\hline
\end{tabular}

HF outcomes: UKPDS: clinical signs/symptoms of HF; ACCORD: fatal/non-fatal HF; ADVANCE: worsening HF, HF hospitalization/death; VADT:

new/worsening HF; SAVOR-TIMI, EXAMINE, TECOS, ACE, ELIXA, LEADER, SUSTAIN-6, EXSCEL, ORIGIN, EMPAREG, CANVAS: HF

hospitalization; ${ }^{\dagger}$ only in intervention group;

NA: not available; Diet: dietary/lifestyle recommendations; SU: sulphonylurea or glinide; MET: metformin; INS: insulin; TZD: thiazolidinedione; INCR: incretin

(GLP-1 receptor agonist or DPP-4 inhibitor); AGI: alpha-glucosidase inhibitor; INS: insulin therapy; SGLT2i: sodium-glucose cotransporter type-2 inhibitor;

LAR: long-acting release 